\title{
Research on Internet of Things Technology Application Status in the Warehouse Operation
}

\author{
Li Juntao, Ma Yinbo \\ School of Information, Beijing Wuzi University, Beijing, China
}

Email address:

Yinbo1991@qq.com (Ma Yinbo)

\section{To cite this article:}

Li Juntao, Ma Yinbo. Research on Internet of Things Technology Application Status in the Warehouse Operation. International Journal of Science, Technology and Society. Vol. 4, No. 4, 2016, pp. 63-66. doi: 10.11648/j.ijsts.20160404.12

Received: June 6, 2016; Accepted: June 14, 2016; Published: July 11, 2016

\begin{abstract}
The internet of things is connected to the Internet, through all kinds of sensing device, the RFID technology, video recognition technology, infrared sensing, global positioning system (GPS), according to the need to implement objects connected to the network of the connectivity, exchange of information and communication, in order to realize intelligent identification, location, tracking and monitoring and management of intelligent network system. First this paper introduces the internet of things technology concrete application in the warehouse operation: the RFID technology; management and control technology; sensor technology. Then discusses the internet of things technology development trend in warehouse operation: the application of RFID technology in warehousing will be rapid development; the integrated application of sensing technology; the AGV will be integrated into the warehouse the Internet of things; the storage and the Internet of things will be the trend of the each other.
\end{abstract}

Keywords: Internet of Things Technology, Intelligent Storage, RFID

\section{Introduction}

The concept of Internet of things is the earliest in the late 1990s, by the EPC global and automatic identification laboratory at the Massachusetts institute of technology. Then, the world's major countries have started a research to the field of Internet of things, and applied to actual production and life based on the results of the study. [1] In 2003, a German retail giant metro company first established the RFID technology was applied to the retail supermarket "future store" concept of the store. Wal-Mart in the United States, followed by the comprehensive application of RFID technology in the company's business, at the same time, the maximum of 100 suppliers issued the last dish, qualified them before January 2005 must be installed on all the goods packing and transportation box RFID tags. The popularity of RFID application, promote the technology of Internet of things a broader range of applications in the whole world, new technology emerge in endlessly. With the accumulation of practical application, the relevant theoretical researches in the field also gradually improve. [2] The United States, the European Union and Japan respectively formulate the radio frequency identification technology, wireless sensor technology, network technology and the application of norms and standards.

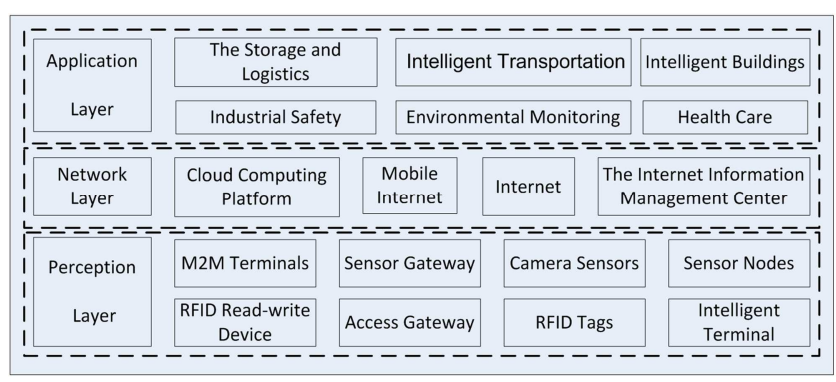

Figure 1. Internet of things architecture.

As interest rates get preliminary application technology, bar code, automatic identification, communication, GPS, data exchange and Internet technology as information technology tools used in the warehouse management step by step, the development of the technology of Internet of things is to let warehouse management more convenient and efficient. [3] Enterprises in the use of new technology in warehouse management, in order to improve the warehouse management information level, each region also began work on the 
Internet of things application construction, to promote the development of the region, Beijing, Shanghai, Shandong and Jiangsu have wisdom city concept, speed up the development of Internet technology applications in the area.

\section{The Internet of Things Technology Concrete Application in the Warehouse Operation}

The Internet of things is something connected to the Internet, it is through all kinds of sensing device, the RFID technology, video recognition technology, infrared sensing, global positioning system (GPS), such as the laser scanner information sensing devices, in accordance with the contract agreement, according to the need to implement objects connected to the network of the connectivity, exchange of information and communication, in order to realize intelligent identification, location, tracking and monitoring and management of intelligent network system. In the intelligent warehouse, in order to achieve perception on warehousing goods, orientation, identification, measurement, sorting, monitoring, etc., mainly uses the sensors, RFID and bar code, laser, infrared, Bluetooth, perception technology such as voice and video monitoring. [4] In warehousing logistics center information system as the core, usually uses the enterprise internal LAN directly connected network technology, and leave with the Internet, wireless network interface, and in the place where is not convenient wiring, generally uses the wireless LAN technology.

\subsection{RFID Technology}

Through RFID technology can realize the scientific and effective management of warehouse location, realize information and limitation of warehouse management. In the warehouse location management system, using RFID positioning system to supervise and control the position, including the position on the map query, distribution, and utilization of goods such as graphic analysis, etc.[5] As a result of the superior function of the RFID technology can realize non-contact, repeated use, fast scanning, and the advantages of large capacity of data and, currently, more and more to be applied to the warehouse location management, on the basis of information and digitization maximum level of improve the efficiency of the warehouse management, improve enterprise's core competitive ability.

Up warehouse location management in wireless networks, covering the entire warehouse, install stationary data terminals in the forklift at the same time, can realize all job data real-time transmission. Wireless data terminal after development can realize confirms the accuracy of location, to verify whether the goods, return to live and work function, at the same time also can accept instructions. In position paste RFID electronic tag, the tag to record the location of the goods and the type information storage, when for warehouse operation staff by reading the electronic tag information, they can record the operation process, accurate management of warehouse location. With RFID technology in warehouse location management, each shelf is accurately recorded the type and quantity of goods, through the automatic guided vehicle RFID read-write device, wireless communications equipment installation, managers can set vehicle periodic inventory of goods in a warehouse, and transmit the inventory results to the system administration center. [6] When the goods need to put in storage, paste the tags for each goods, general labels can be pasted into the tray, or set to realize the reuse of the tray. When the goods enter the goods can read the label information and compared with the location information, determine if the operation is properly.

RFID inventory location management is proposed, which can realize the arrival of the goods from a warehouse inspection, inbound, outbound, allocate, shift of the library, inventory data in each operation link, such as automatic data acquisition, ensure warehouse management each link data input speed and accuracy, ensure the timely and accurately grasp the inventory of the enterprise real data, reasonable to maintain and control business inventories, improve enterprise's core competitive ability.

\subsection{Management and Control Technology}

At present, can achieve the whole process of intelligent control and management of the logistics is not much, also only stay in the Internet of things and logistics information to automatic recognition, automatic perception, automatic positioning, process tracing, online tracking, online scheduling application level in general.[7] In expert systems integration and information sharing, data mining, network optimization, intelligent scheduling and line automatic adjustment management there are great gap between the applications of intelligent management technology. Part in enterprise logistics system, logistics system can also be combined with seamless enterprise production management system, intelligent operation; Part of the intelligent and automation of logistics center can be fully automated and intelligent logistics operation.

\subsection{Sensor Technology}

As an important means of access to information, sensor technology and communication technology, computer technology constitutes the three pillars of the information technology. Sensor is IOT perception layer of the main components, help IOT information timely and accurate access to external physical world. Formed by the combination of sensors and communication network of sensor network technology, laid the foundation for the development of the Internet of things the warehouse of the sensing system is mainly used for monitoring of environmental and items, to meet the requirements of the goods to the environment and security monitoring.

Sensing system consists of mainly sensor of a variety of sensing equipment (include image sensors, sonar sensors) is used widely in a warehouse management of multi-functional system. [8] Sensor is a device that converts physical 
measured signal, sensor selection need according to the requirement of the environment or item, can choose to collect physical, biological and chemical effect was related to measuring sensor for the construction of the system. In general, most of ordinary warehouse items (such as temperature, humidity, etc.) to the environment have common requirements, so in general warehouse location should set up the environment special sensors, this kind of sensor can be a variety of measurements in integrated induction environment to meet the requirements of the general goods.

To the requirement of special goods or special business often require more functions defined area and set up the integrated sensor, such as gravity, pressure, gas density, and sensor noise, etc. Integrated function in the number of sensors is more expensive, is not easy to use fixed, when the goods change or item requirements change, can the position of the mobile sensor, and according to the demand for open and closed part of the service, improve the utilization rate of the sensor.

\section{The Internet of Things Technology Development Trend in Warehouse Operation}

\subsection{The Application of RFID Technology in Warehousing Will Be Rapid Development}

RFID is a non-contact automatic identification technology, it through radio frequency signal automatically identify target objects and access to relevant data, identify work without manual intervention, it can work in all kinds of bad environment. [9] RFID technology can identify the high-speed movement of objects and identify multiple tags at the same time, the operation is convenient. The development of the Internet of things for the application of RFID in warehousing brought the good development opportunity. With the development of the Internet of things technology, in the field of storage, the application of RFID will, gradually expand to wider areas, and traces the logistics system integration and product intelligence, greater benefits.

RFID as a new kind of logistics information technology applied to warehousing logistics just solved the problem of the warehousing logistics in the information does not match, through the data and information non-contact rapid transmission, real-time tracking and information collection and monitoring, improve the efficiency of goods inventory acceptance, implementation in the library items fast query, reduce the items in the inventory time, improve the efficiency of outbound sorting items. Real-time tracking characteristics make it has the function of visualization is applied to the modern warehouse and logistics management, will enhance the level of the whole logistics industry information.

\subsection{The Integrated Application of Sensing Technology}

In IOT perception interactive layer, information processing technology mainly complete sensor data preprocessing, target/event detection, target feature extraction and optimization, data aggregation, and other functions, with the aid of information processing technology, the Internet of things perceived interactive layer can also be completed preliminary judgment of target attribute even simple prediction information of target state is given. In Internet application service layer, information processing technology mainly complete knowledge generation, situational analysis, information mining, data search, information feedback and decision making, and other functions.

With the aid of perception technology integration application, in the special goods warehouse monitoring system, can be used in environmental monitoring, warehouse to meet environmental parameters such as temperature, humidity, air composition of distributed monitoring demand, realize the intelligent storage environment. [10] Application of wireless sensor network (WSN) in dangerous goods logistics management, real time monitoring and a state of containers of dangerous goods, once more than alert value can timely alarm, thus for dangerous goods logistics process of tracking, monitoring, management, etc. In the cold storage logistics system, can monitor all the frozen products in the environment of temperature and humidity, regulating the temperature and humidity in time, ensure the quality of products.

\subsection{The AGV Will Be Integrated into the Warehouse the Internet of Things}

With the development of sensor technology and information technology, AGV (Automated Guided Vehicle, AGV) also move in a direction to the intelligent direction, and therefore also known as intelligent AGV. In recent years, with the application of Internet technology, the fully automated intelligent logistics center, $\mathrm{AGV}$ as an important component of the Internet of things, to become a logistics terminal with wisdom, and the Internet of things networking operation of logistics system, intelligent operation, to achieve the wisdom logistics. [11] Believe that, with the development of Internet technology and the application of intelligent technology will make the $\mathrm{AGV}$ to obtain a more wide development.

With the development of the Internet of things technology, $\mathrm{AGV}$ is more and more become the indispensable important component of the Internet of things, this section as a logistics terminal with wisdom, and the Internet of things networking operation of logistics system, interaction function operation, realizing the intelligent logistics. The intelligent truck after receiving orders released to the logistics system, based on the rolls to the mobile data, mobile library, Chambers to ensure that items emissions more reasonable, scientific and security.

\subsection{Storage and the Internet of Things Will Be the Trend of Each Other}

At present, the technology of the Internet of things is limited to application in a separate warehouse distribution 
center internal network, still is independent, local intelligent storage system. With the help of the Internet of things technology, the independent intelligent warehouse system connected to the Internet, break the information island, realize each other, form the real storage and Internet of things, is based on intelligent storage produce new change, it will be a revolution of storage information.

Intelligent storage system based on Internet of things technology to improve traditional warehousing internal storage, inventory, low efficiency of process links such as environmental monitoring, improve the efficiency of storage and internal links of information transmission, storage of inventory, the environment and for the real-time sharing of information. For warehouse management, can achieve the real-time control of warehouse within all kinds of information, to avoid the information lag problem by manual work, the Internet of things technology reference to traditional warehousing did good optimization process, from information gathering to information processing and finally to the upper business information application has realized the real-time, accurate and efficient, sped up the upper business efficiency, give full play to the warehousing link allocation function, improve the storage service.

\section{Conclusion}

Combined with Internet of things application in warehouse operation status and the development of the Internet of things form, Internet of things will be the next important productive forces and to promote the development of world economy high speed from the point of view of the technical architecture, the Internet by the perception layer, network layer and application layer constitute, the perception layer mainly embodied in all kinds of sensors and sensors; The network layer is mainly embodied in the Internet, wireless communication network such as network; Its applications are mainly embodied in the user effective connection with the Internet of things. To ensure that the Internet of things in logistics warehouse management system the effective application needs to make good use of sensing technology, the RFID technology and embedded system technology. In addition, according to the nature of the Internet of things application can be divided into three basic models: smart tags, environmental regulation and the object tracking and intelligent control of objects. At present, the application of Internet of things in our country is in the primary stage, only the implementation of the "content" of networking. The Internet of things has been used in the logistics warehouse management system, but its efficiency can function in the logistics warehouse management system into full play, so you need to logistics enterprise combining with the Internet of things system, make appropriate adjustments to logistics information system, is committed to the Internet of things, actively use modern logistics technology and equipment, promote the change of wisdom logistics, logistics warehouse management system to ensure the long-term sustainable development.

\section{Acknowledgements}

The study is supported by Beijing Intelligent Logistics System Collaborative Innovation Center and Intelligent Logistics System Beijing Key Laboratory (NO: BZ0211).

\section{References}

[1] Wu Gongyi, Wu Ying. An introduction to the Internet of things engineering [M]. Beijing: Mechanical industry publishing house. $2012,35-60$

[2] Wang Xifu. IOT and modern logistics [M]. Beijing: Electronic industry press. 2013

[3] Liujun. Storage and control integration system design strategy based on Internet of things [J]. Journal of logistics technology. 2011.30 (8).

[4] $\mathrm{Wu}$ Xiaozhao. IOT technology application analysis and prospect in the field of logistics [J]. 2011 (6) China's circulation economy.

[5] Huang Lili, Zhang Zhiyong. Internet of things technology in the application of logistics warehousing management system [J]. China collective economy. 2012 (2)

[6] Zhang Renbin. Warehouse management system based on Internet of things technology research [J]. Journal of logistics technology. 2011 (6)

[7] Li Zhongchen. The design and implementation of intelligent storage and Internet of things [J]. Computer application system. 2011 (6)

[8] Huang Zhiyu. Intelligent logistics warehousing system research of Internet of things [J]. Automation instrument. 2012 (32)

[9] Liu Huating, Yang Huayun. Storage and control integration architecture design based on Internet of things [J]. Logistic theory. 2013 (10)

[10] Wang Xifu, Su Shuping. IOT and modern logistics [M]. Beijing: electronic industry press, 2013.

[11] Xu Huijian. Warehousing information collection and management of radio frequency identification system design [J]. Journal of wireless communication technology, 2010 (2): $52-56$ 